\title{
Developing a scale to measure students' attitudes towards fanaticism
}

\author{
Karim Alzangana \\ Department of Psychology, College of Education, University of Garmian
}

\begin{abstract}
The purpose of the current study was to develop a scale to evaluate students' attitudes towards fanaticism. In order to do this, the researcher composed a questionnaire of 64 items. The format of the questionnaire corresponded to the five-point Likert Scale: 1 strongly agree; 2 agree; 3 slightly agree; 4 strongly disagree; and 5 disagree. The research sample consisted of 23 undergraduate students from the University of Leicester. The research tool was an online questionnaire distributed through the.EPR system. Participants completed the questionnaire in return for course credit. Results of statistical analysis, obtained through the use of Statistical Package for the Social Sciences (SPSS), were as follows. The internal reliability (Cronbach's Alpha) of the final structure of the scale, which consisted of 20 items, was calculated to be $\alpha=$.834. Statistical analysis (principal components analysis, orthogonal approach, Varimax method) resulted in the following three factors: factor 1, "Fanaticism and social security" (8 items highly loaded on this factor); factor 2, "Religious fanaticism" (9 items highly loaded on this factor); factor 3, "Fanaticism and absolute views" (3 items highly loaded on this factor). These three factors explained $52.516 \%$ of the variance.
\end{abstract}

Fanaticism is an internal feeling which causes an individual to believe that his/her opinions and ideas are permanently on the right side of truth. Fanatics simply do not accept the need for debate and view people with different opinions to their own as presenting a threat to their values and beliefs. Fanatical beliefs can result in discrimination and sometimes aggressive behaviour towards people who hold alternative opinions and beliefs.

Fanaticism is a serious social and psychological issue which could present a significant risk to the community: "Fanatical beliefs may possibly lead to a nuclear holocaust in the nottoo-distant future" (Ellis, 1986). Investigating intolerance and fanaticism from a psychological and social standpoint using scientific research could help to identify some of the causal factors related to these phenomena. Ultimately, this research could help to achieve recognition accuracy 'More effective recognition and a clearer understanding of fanaticism, thereby making it easier to deal with and, potentially, reducing its impact on society. 
Fanaticism is one of the most prevalent social and psychological phenomena in the world today. There has been no community that has not been affected by some form of fanaticism. Although the phenomenon of fanaticism is linked to various political and religious ideas and beliefs, it can manifest in many different areas of human activity. Marimaa (2011) pointed out that fanaticism is a universal phenomenon which can appear in any sphere of human activity.

A fanatic is someone who holds certain views or ideas that he or she believes to be absolutely true; doubts are never entertained. Such a person tends to view those with different views as evil or even, in some way, "inhuman" (Peter, 2011). Furthermore, a fanatic will defend these particular ideas vigorously, sometimes going so far as to attack those who do not believe them to be valid. A fanatic holds rigidly to his point of view and is intolerant of those who disagree with him. The Macmillan Dictionary describes a fanatic as "someone who has very strong religious or political beliefs that often make them behave in an unreasonable way".

Fanaticism from the psychological perspective is a personality disorder not greatly different from other phobias and neurotic conditions. A fanatic is a person who could pose a major threat to the fabric of society. For this reason it has become an important topic in many areas of psychological and social studies. A fanatic is more than just a narrow-minded and dogmatic person. S/he tries zealously and by all means to impose her/his convictions on others." (Marimaa, 2011). However, some researchers believe that fanaticism is not always a negative phenomenon. Marimaa (2011) pointed out that fanaticism could be positive or negative depending on the behaviour of an individual fanatic and the reasons that lead someone to become fanaticized over a particular issue.

Fanaticism is a learned behaviour, not an instinctive behaviour. Humans acquire this behaviour through the social environment and the ideas and beliefs existing in the community. Religious and political beliefs are those which can lead to the most dangerous forms of fanaticism. These were, and still are, the main causes of many bloody conflicts.

Based on the above analysis, studying fanaticism from a scientific standpoint and using scientific research may help to clarify the mechanics of this rather vague phenomenon. More effective approaches to dealing with fanaticism could be a result of this method of study. It could thus contribute to reducing the impact of this phenomenon on both the individual and society. 
The importance of this research lies in trying to build a tool capable of measuring one of the most dangerous phenomena that threaten the social fabric and cause many mental and behavioural disorders. This serious problem which poses a threat to the mental health of affected individuals. Fanaticism also has the potential to produce crises throughout society, whether affecting the political, social or psychological spheres. A scientific approach to fanaticism is likely to provide new and valuable insights into the phenomenon.

\section{Method}

\section{Participants}

23 undergraduate students (male and female) from the School of Psychology at Leicester University (2013-2014) participated in this study.

\section{Apparatus}

An attitude questionnaire (consisting of 64 items), based on a review of related literature, was developed. The five-point Likert Scale was used as the format of the questionnaire: 1 strongly agree; 2 agree; 3 slightly agree; 4 strongly disagree; and 5 disagree.

\section{Procedure}

Ethical approval was obtained before conducting this study. The research was conducted by an online questionnaire distributed through EPR system. Participants completed the questionnaire in return for course credit. The questionnaire required approximately 20-25 minutes to complete.

\section{Statistical analysis}

The Statistical Package for the Social Sciences (SPSS) version 20.0 for Windows was used to conduct the statistical analysis. Cronbach's Alpha technique was used to investigate the internal reliability of the scale.

Exploratory factor analyses were used in this study including extraction and rotation techniques. "Exploratory factor analysis allows one to make sense of a complex set of variables by reducing them to a smaller number of factors which account for many of the original variables" (Howitt \& Cramer, 2008).

Principle component analyses were performed. Principle component analysis is essentially a method of data reduction that aims to produce a small number of derived 
variables that can be used in place of the large number of original variables. This simplifies the subsequent analysis of the data (Landau \& Everitt, 2004).

\section{Results}

Internal reliability of the scale:

Firstly, as can be seen from Table 1, the output of the internal reliability analysis shows that a low Cronbach's Alpha for 64 items was interred in the analysis (Cronbach's Alpha for 64 items, $\alpha=.447)$.

Table (1) Cronbach's Alpha for 64 items.

\begin{tabular}{|l|l|l|}
\hline \multicolumn{2}{|c|}{ Reliability Statistics } \\
\hline Cronbach's Alpha & & No of Items \\
\hline .447 & & 64 \\
\hline
\end{tabular}

This value was not satisfactory for the scale. In order to improve the internal reliability of the scale, corrected item-total correlation and Cronbach's Alpha if Item deleted- one item at a time method was used. For "any items that have value of $\alpha$ in the column labelled 'Cronbach's Alpha' if Item deleted that are substantially greater than the overall $\alpha$ may need to be deleted" (Field, 2005). For example, Table 2, below, shows that if the item "all human beings are equal in mental and cognitive capacity and the only differences between them relate to their circumstances" is deleted, the internal reliability (Cronbach's Alpha) of the scale will improve from .447 to .508 .

Table 2: internal reliability (Cronbach's Alpha if item deleted).

\begin{tabular}{|c|c|}
\hline Item & $\begin{array}{c}\text { Cronbach's Alpha if } \\
\text { Item Deleted }\end{array}$ \\
\hline $\begin{array}{c}\text { All human beings equal in } \\
\text { mental and cognitive capacity } \\
\text { and the only differences between } \\
\text { them relate to their circumstances }\end{array}$ & .508 \\
\hline
\end{tabular}

In order to obtain an appropriate internal reliability for our scale, the process of deleting items which, in the first instance above, improved the Cronbach's Alpha for the scale, was continued. After deleting 44 items, the internal reliability of our scale improved to reach Cronbach's Alpha for 20 items, $\alpha=.834$ (Table 3). This, according to Kline (2000), is an appropriate value for internal reliability for scale. 
Table 3: Cronbach's Alpha for 20 items

\begin{tabular}{|c|c|}
\hline \multicolumn{2}{|c|}{ Reliability Statistics } \\
\hline Cronbach's & Number of \\
\hline Alpha & Items \\
\hline .834 & 20 \\
\hline
\end{tabular}

\section{Factor analysis}

An exploratory factor analysis was performed to explore whether there is a fundamental structure in the pattern of correlation between our variables. Factor analysis was also used to evaluate the appropriateness of data for factor analysis. This process included examining the correlation matrix for a coefficient of 0.30 and above. Kline (1986) suggested ignoring any score less than 0.3 (cited in Maltby, 2013), while other authors suggested 0.4 and above (Maltby, 2013). Applying the Kaiser-Meyer-Olkin [KMO] criterion to examine the adequacy of our sample and using Bartlett's test of sphericity. As can be seen from Table 4, KMO=.221 which is not an adequate value for factor analysis (this could be because of the small number of participants in our study' KMO index ranges from $0-1$, with .6 suggested as minimum). However, Bartlett's test of sphericity was 280.43 and was significant $\mathrm{p}<05$.

Table 4: KMO and Bartlett's Test

\begin{tabular}{|c|c|c|}
\hline $\begin{array}{l}\text { Kaiser-Meyer-Olkin } \\
\text { Adequacy. }\end{array}$ & Measure of Sampling & .221 \\
\hline \multirow[t]{3}{*}{$\begin{array}{l}\text { Bartlett's Test of } \\
\text { Sphericity }\end{array}$} & Approx. Chi-Square & $\begin{array}{r}280 . \\
435\end{array}$ \\
\hline & df & 190 \\
\hline & Sig. & .000 \\
\hline
\end{tabular}

Principal components analysis was performed in order to determine how many components (factors) to extract. Kaiser's criterion (eigenvalue) was considered to determine the number of the components (factors) "Eigenvalue is a measure of how much variance in the data is explained by a single factor" (Brace, Kemp, Snelgar, 2006). The default value in SPSS is 1.0 or more. Kaiser (1960) suggested all factors with eigenvalues larger than 1 should be retained (cited in Field, 2013). According to this criterion the components that have an eigenvalue of 1 or more should be considered as factors. From Table 5 it can be seen that only the first 6 components recorded eigenvalues above 1. These 6 components explain a total of $76.334 \%$ of the variance. 
Table 5: Total Variance Explained

\begin{tabular}{|c|c|c|c|c|c|c|}
\hline Component & \multicolumn{3}{|c|}{ Initial Eigenvalues } & \multicolumn{3}{c|}{ Extraction Sums of Squared Loadings } \\
\hline & Total & \% of Variance & Cumulative \% & Total & \% of Variance & Cumulative \% \\
\hline 1 & 5.222 & 26.108 & 26.108 & 5.222 & 26.108 & 26.108 \\
\hline 2 & 3.156 & 15.782 & 41.891 & 3.156 & 15.782 & 41.891 \\
\hline 3 & 2.125 & 10.625 & 52.516 & 2.125 & 10.625 & 52.516 \\
\hline 4 & 1.843 & 9.215 & 61.730 & 1.843 & 9.215 & 61.730 \\
\hline 5 & 1.540 & 7.701 & 69.431 & 1.540 & 7.701 & 69.431 \\
\hline 6 & 1.380 & 6.902 & 76.334 & 1.380 & 6.902 & 76.334 \\
\hline
\end{tabular}

By applying Kaiser's criterion to the above table, there are many components to be extracted. To determine how many factors are appropriate to retain, it is necessary to refer to a scree plot. (Figure 1)

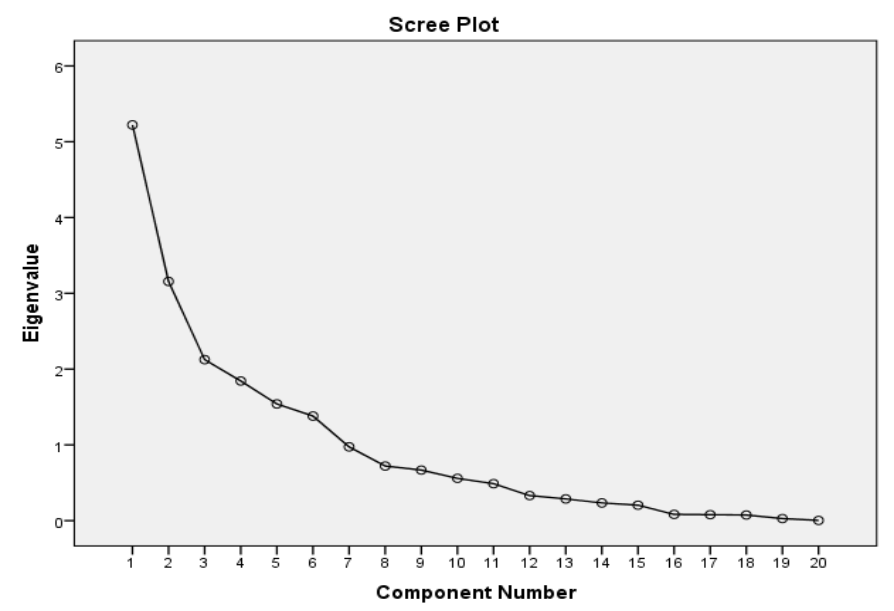

Figure 1: scree plot

As indicated in the above scree plot, there is a clear break between the third and fourth components. In addition, factors 1,2 and 3 explain much more of the variance than the other factors. So I decided to retain just 3 factors. The percentage of variance explained by these three factors was 52.516 .

In the final stage, factor rotation (orthogonal approach, Varimax method) technique was performed in order to interpret the items and minimize the number of variables which have high loading on each factor.

As can be seen in Table 6, there were 8 items which were highly loaded on factor 1,9 items which were highly loaded on factor 2 , and 3 items which were highly loaded on factor 3 .

Finally, after referring again to Table 6 (Rotated Component Matrix) to find which variables load on which factor, it was necessary to find suitable names for each factor "People 
name factors by deciding what the related variables have in common" (Dancy \& Reidy, 2007). Factor 1 was named "Fanaticism and social security", because the 8 items which loaded on this factor related to the danger of fanaticism to society. Factor 2 was named "Religious fanaticism", as the 9 items that loaded on factor 2 , this factor..' were related to religion. Factor 3 was named "Fanaticism and absolute views", representing the viewpoints contained in the 3 items that loaded on this factor.

Table 6: Rotated Component Matrixa

\begin{tabular}{|c|c|c|c|}
\hline & Compone & & \\
\hline & 1 & 2 & 3 \\
\hline 1. Fanaticism breeds violence and causes disaster for society & .777 & & \\
\hline $\begin{array}{l}\text { 2. I am always right, but others cannot understand my } \\
\text { thoughts. }\end{array}$ & .676 & & \\
\hline $\begin{array}{l}\text { 3. Intolerance is a phenomenon which could lead to a } \\
\text { disintegration of the fabric of society }\end{array}$ & .630 & & \\
\hline $\begin{array}{l}\text { 4. Fanaticism is a kind of intellectual terrorism that must be } \\
\text { fought }\end{array}$ & .457 & & \\
\hline $\begin{array}{l}\text { 5. The multiplicity of religions is a cultural phenomenon } \\
\text { which must be protected }\end{array}$ & & .661 & \\
\hline $\begin{array}{l}\text { 6. Fanaticism is a form of intellectual stagnation which does } \\
\text { not comply with civil society }\end{array}$ & & .622 & \\
\hline $\begin{array}{l}\text { 7. There is only one true religion and all other religions are } \\
\text { invalid }\end{array}$ & & .586 & \\
\hline $\begin{array}{l}\text { 8. When somebody disagrees with your point of view it is } \\
\text { tantamount to a direct insult to your personality }\end{array}$ & & .560 & \\
\hline $\begin{array}{l}\text { 9. Fanaticism is a serious social disease and must be fought } \\
\text { in every way }\end{array}$ & & .543 & \\
\hline $\begin{array}{l}10 \text { Religion must be imposed on people by any means, even } \\
\text { force }\end{array}$ & & .498 & \\
\hline $\begin{array}{l}\text { 11-I cannot respect people who constantly change their } \\
\text { opinions. }\end{array}$ & & .481 & \\
\hline $\begin{array}{l}\text { 12-Fanaticism exists in all beliefs and does not apply only to } \\
\text { any one particular belief }\end{array}$ & & .400 & \\
\hline $\begin{array}{l}\text { 13-Fanaticism is an abnormal phenomenon in all civilized } \\
\text { societies }\end{array}$ & & & .908 \\
\hline 14-Fanaticism is learned from one's social environment & & & .778 \\
\hline 15-Religious fanaticism is the most dangerous form of & & & .709 \\
\hline
\end{tabular}




\begin{tabular}{|c|c|c|}
\hline fanaticism because it is perpetrated in the name of God & & \\
\hline 16-Fanaticism is the beginning of the road towards terrorism & .816 & \\
\hline $\begin{array}{l}\text { 17-Consulting others when making a decision is a waste of } \\
\text { time and effort }\end{array}$ & 679 & \\
\hline $\begin{array}{l}\text { 18-Customs and traditions are obsolete social phenomena, } \\
\text { therefore we should not believe in them }\end{array}$ & .668 & \\
\hline $\begin{array}{l}\text { 19-Fanaticism is one of the rarest phenomena in communities } \\
\text { and therefore does not deserve a lot of attention }\end{array}$ & .468 & \\
\hline $\begin{array}{l}\text { 20-A fanatic is somebody who is suffering from a } \\
\text { psychological disorder }\end{array}$ & & .696 \\
\hline
\end{tabular}

\section{Discussion}

The aim of this study was to develop an appropriate scale which is capable of measuring the attitudes of students towards fanaticism. In order to achieve this, the researcher built a scale consisting of 64 questions based on previous studies and theoretical literature.

The first important step in this study was to verify the internal reliability of the scale. For this the researcher used the Statistical Package for the Social Sciences (SPSS) version 20.0 for Windows (reliability analysis). The result of the analysis showed a low value of internal reliability for 64 items, $\alpha=.447$. Unfortunately, this value is not an appropriate value for internal consistency of scale. Brace et al (2012) indicated that a scale should have a minimum Cronbach's Alpha value of .7. This result prompted the researcher to use a technique common in similar research, corrected item-total correlation and Cronbach's Alpha if Item deleted- one item at a time method. This technique was used to exploit the table produced by the analysis of internal consistency (Item-Total Statistics table).

A process of deleting items, which analysis showed would help improve the internal consistency of the scale, was followed. After deleting 44 items, internal consistency improved to reach Cronbach's Alpha for 20 items, $\alpha=.834$. According to Brace et al (2012) this value was considered an appropriate one for internal reliability of a scale.

Internal consistency of the scale is one of its most important characteristics. Internal consistency refers to the extent of the homogeneity and the relationship between the items' "reliability means that a measure or questionnaire should consistently reflect the construct that it is measuring" (Field, 2013). 
The second essential step in the procedure was to investigate the adequacy of our data for factor analysis. The Kaiser-Meyer-Olkin [KMO] criterion was used to examine this condition. The result of analysis produced an inadequate value which indicated that our data would not be appropriate for good factor analysis. As already mentioned, this could be because of the small number of our sample. Tabachinck \& Fidell (2013) recommended 0-1 with .6 as the minimum value for a good factor analysis. There are several views regarding the number of participants considered to be appropriate for factor analysis. Fidell (2013) suggested 300 cases for factor analysis (cited in Pallent, 2013). Other authors suggest ratios of participants to items. Nunally (1978), for example, recommended a ratio of 10-1 (cited in Pallent, 2013). Nonetheless, the result of Bartlett's test of sphericity was 280.43 and was significant $\mathrm{p}<05$.

The third step in our research procedure was to find out how many factors we can extract from our data. To achieve this, principal components analysis was performed. According to the eigenvalue rule (Kaiser's criterion), the result shows that we can extract 6 factors. The eigenvalue rule is one of the most commonly used methods. Applying this rule, only the factors with eigenvalues of 1 or more are retained (Pallant, 2013). Nevertheless, from a closer look at the scree plot of the results, it is noticed that there is a clear break between the third and fourth components and, also, that the factors 1, 2 and 3 explain $52.516 \%$ of the variance. The researcher thus decided to retain these three factors. Cattel (1966) recommended that on the plot we should try to find a point at which the shape of the curve changes its direction and only retain the factors above this point. This is because these factors are responsible for explaining much more variance than the other factors (cited in Pallant, 2013).

To minimize the number of variables which have high loading on each factor, the orthogonal approach, Varimax method has been used. The result shows that 8 items loaded on factor 1, 9 items on factor 2 and 3 items on factor 3 . Although the numbers of items which loaded highly on factors 1 and 2 are appropriate, the number of items which loaded highly on factor 3 does not look appropriate. So it could create a weakness in the scale. In fact, developing a new scale in psychology would not be easy to achieve because of the many skills and verity of knowledge required. 
One of the most important limitations of this study is likely to be the inadequate number of participants. In this study we used only 23 participants; according to previous studies this sample is of insufficient size for factor analysis.

Overall, and in recognition of the fact that this study needs developing in the future, we can argue that our scale may serve as valuable groundwork for other studies in this area. This study is particularly significant in its construction of a scale capable of measuring people's attitudes toward fanaticism. Such an approach is very rare for an investigation of this nature. As we have mentioned in the introduction to this investigation, fanaticism is a very important issue in many societies and to study it from a scientific standpoint could result in valuable insights. These could be of help to psychologists in discovering the causes of fanaticism and, consequently, in finding effective ways to reduce its threat to the security of our society.

\section{References}

Brace, N., Kemp, R., \& Snelgar, R. (2012). SPSS for psychologists. Palgrave Macmillan.

Dancey, C. P., \& Reidy, J. (2007). Statistics without maths for psychology. Edinburgh, Pearson Education.

Ellis,P.(1986).Fanaticism that may lead to a nuclear holocaust.[online].Available at: http://birdviewjoey.blogs.com/integral/files/fanaticism_that_may_lead_to_a_nuclear_ holocaust.pdf.

Field, A. (2013). Discovering statistics using IBM SPSS statistics.Sage.

Howitt, D., \& Cramer, D. (2008). Introduction to SPSS in psychology: For version 16 and earlier. Edinburgh, Pearson Education.

Kline, P. (2013). Handbook of psychological testing. Routledge.

Landau, S., \& Everitt, B. (2004). A handbook of statistical analyses using SPSS (Vol. 1). Boca Raton, FL: Chapman \& Hall/CRC.

Macmillan Dictionary. [online]. Available at: http://www.macmillandictionary.com/.

Maltby, J., Day, L., \& Macaskill, A. (2010). Personality, individual differences and intelligence. Edinburgh, Pearson Education.

Marimaa, k. (2011). The many faces of fanaticism. [online]. Available at: http://www.ksk.edu.ee/wpcontent/uploads/2012/12/KVUOA_Toimetised_14_2_kalme r_marimaa.pdf.

Pallant, J. (2010). SPSS survival manual: A step by step guide to data analysis using SPSS. McGraw-Hill International.

Peter, G. (2011) [online) available on http://www.psychologytoday.com/blog/sex-drugsand-boredom $/ 201103 /$ the-fanatic-and-the-addict].

Tabachnick, B. G., \& Fidell, L. S. (2001). Using multivariate statistics. Edinburgh, Pearson Education. 